1. MBBS, M.Phil

Assistant Professor

Departemnt of Pharmacology

Isra University, Hyderabad, Sindh, Pakistan

2. MBBS, M.Sc. M.Phil

Professor

Department of Pharmacology

Isra University Hyderabad, Sindh, Pakistan.

3. MBBS, M.Phil

Assistant Professor

Departemnt of Biochemistry

Isra University, Hyderabad, Sindh, Pakistan.

4. MBBS, M.Phil

Assistant Professor

Departemnt of Pharmacology

Isra University, Hyderabad, Sindh, Pakistan.

5. MBBS, M.Phil

Assistant Professor

Department of Pathology

Isra University Hyderabad, Sindh,

Pakistan

\section{Correspondance Address:}

Dr. Palwasha Abbasi

Departemnt of Pharmacology, Isra

University,

Hyderabad, Sindh, Pakistan.

palwasha_abbasi12@outlook.com

Article received on:

28/02/15

Accepted for publication:

07/05/2015

Received after proof reading:

08/08/2015

\section{HYPERGLYCEMIA; CATHARANTHUS ROSEUS \& NIGELLA SATIVA AMELIORATE IN ALLOXAN INDUCED DIABETIC RATS}

\author{
Dr. Palwasha Abbasi ${ }^{1}$, Dr. Abdul Rahim Memon ${ }^{2}$, Dr. Sadia Tabassum Abbasi ${ }^{3}$, Dr. Sadia Kazi ${ }^{4}$, \\ Dr. Shomail Siddiqui ${ }^{5}$
}

\begin{abstract}
Objectives: To investigate blood glucose regulaitng effects of Catharanthus Roseus (C.roseus) and Nigella sativa (N.sativa) in alloxan induced diabetic rats. Study Design: Experimental study. Place and Duration: Animal house Isra University Hyderabad. From April to Novermber 2013. Methodology: 50 male rats were housed at normal température, 12 hour dark - light cycle with free access to chow and water. A single intraperitoneal bolus of alloxan (120 mg/kg) was given to induce diabetes mellitus. Glimepiride, C. roseus and N. Sativa were administered at doses of $0.1 \mathrm{mg} / \mathrm{kg}, 125 \mathrm{mg} / \mathrm{kg}$ and $50 \mathrm{~g} / \mathrm{kg}$ respectively. Data was analyzed on SPSS version 21.0. Significant $P$ - value was defined at $\leq 0.05$. Results: C.roseus ad N.sativa showed blood glucose lowering potential but the effect was less when compared to glimepiride $(P=0.001)$. However, $C$. roseus was more effective compared to N.sativa $(P=0.001)$ in reducing blood glucose. Findings suggest that both $\mathrm{C}$. roseus and $\mathrm{N}$. sativa possess glucose regulating potential. Conclusion: It is concluded that the $\mathrm{C}$. roseus and $\mathrm{N}$. sativa exert blood glucose regulating effects in alloxan induced diabetic rat model.
\end{abstract}

Key words: $\quad$ Catharanthus roseus, Nigella sativa, Alloxan, Rats

\section{INTRODUCTION}

Diabetes mellitus (DM) is a metabolic disorder characterized by chronic hyperglycemia caused by defective insulin secretion or its physiological function. Insulin deficiency disturbs metabolism of glucose, proteins and fats equally. World over, $\mathrm{DM}$ is the 5th leading cause of death. DM causes microvascular complications and increases mortality and morbidity due to complications. ${ }^{1}$

Many plants have been used for controlling hyperglycemia in diabetics. Reported herbs and plants include; Nigella sativa, Terminalia-pallida, Cogent $\mathrm{db}$, Myrtus communis, Mucuna pruriens,
Eugenia jambolana, Bauhinia forficata koeingii, Tinospora cordifolia, Lactuca indica, Momordica charantia, Oivieri-griseb and Aporosa lindleyana Baill. C. roseus has also been reported for lowering of blood glucose in diabetics. ${ }^{2,3}$ Previous studies had reported that these herbs and plant inhibit and delay the complications of DM also. ${ }^{3}$

In English, C. roseus is known as Madagscar periwinkle while in Southeast Asia, it is famous as Sadabhar. Previous studies had reproted antihypertensive, anti-mutagenic, anti-fungal, antispasmodic, anti-cancer, anti-malaria, and lipid lowering effects of $\mathrm{C}$. roseus. Anti-diabetic acivity 
has also been attributed to C. roseus. ${ }^{4} \mathrm{~A}$ previous study reported anti-hyperglycemic activity of $\mathrm{C}$. roseus in alloxan induced diabetic rat model. ${ }^{5}$ Studies had reported that the leaf juice of $\mathrm{C}$. roseus exerts more prolonged glucose lowering than glibenclamide at a dose of $1.0 \mathrm{ml} / \mathrm{kg}$ and multiple cellular mechanisms had been proposed for its glucose lowering effects. Glucose lowering effects are exerted by its active ingredients like, vindoline, vindolinine and catharanthine..$^{5,6}$

N. sativa belongs to Ranunculaceae family and is strong spicy herb. It is commonly known as black cumin. ${ }^{7}$ Previous studies had reproted $\mathrm{N}$. sativa as remedy for many disease such as acute bronchitis, auto-immumne disease, bacterial infection, hypertension ${ }^{8}$, liver ailments, gastrointestinal disorders and allergic disease. ${ }^{9}$ It is honored say of Holy Prophet (SAW) that the $\mathrm{N}$. sativa cures all diseases except the death. ${ }^{10}$ Beneficial effects of $N$. sativa had never been fully scrutinized, as it showed multiple beneficial effects to avert many chonic diseases. N.sativa is claimed of exerting insulinotropic action ${ }^{11,12}$ and inhibiting liver gluconeogensis. ${ }^{13}$ Anti-oxidative properties of $\mathrm{N}$. sativa are produced by inhibition of eicasonoid synthesis and lipid peroxidation of membrane phospholipids. Thymoquninone is though to be the active ingredient of N.sativa and anti-hyperglycemia activity is attributed to it. ${ }^{14}$ The rationale of present study was to evaluate blood glucose lowering effects of C.roseus and N.sativa in alloxan induced diabetic rats in comparison to glimepiride.

\section{MATERIALS AND METHODS}

An experimental study was conducted at the Animal house of Isra University, Hyderabad, Sindh from April 2013 to November 2013. A sample of 50 male Wistar albino rats was selected. Male Wistar Albino rats of 200 - 300 grams were included, while female rats, sick and moribund animals were excluded. Animals were weighed, tagged, and were kept in separate stainless steel cages at normal temperature, 12 hour dark-light cycle and free access to chow and water. Rats were divided into five groups as ; Group A: control (n =10), Group B: diabetic (alloxan treated control)
( $n=10)$, Group C: diabetic was treated with C. roseus $(n=10)$, Group $D$ : was treated with $N$. sativa $(n=10)$, Group E: diabetic rats treated with glimepiride $(n=10)$.

DM was induced in animals except the control group by single intraperitoneal injection of Alloxan (Sigma Company) at the dose of $120 \mathrm{mg} /$ $\mathrm{kg}$ dissolved in $0.5 \mathrm{ml}$ of acetate buffer. 2 - 3ml of blood was drawn from the tail vein. Blood was collected in gel tubes and centrifuged at 4000 rpm for 5 minutes to obtain serum.

Blood samples were taken on days 0, 7 and 14 . Body weight was measured simultaneously. The blood glucose level was checked on HITACHI 902 CHEMICAL ANALYZER (Hitachi, Roche, USA). DM was defined as random blood sugar $>200 \mathrm{mg} / \mathrm{dl}$ on three successive days. Glimepiride $1 \mathrm{mg}$ tablet (Amaryl, Sanofi Aventis) was purchased from local pharmacy and administered orally at the dose of $0.1 \mathrm{mg} / \mathrm{kg}$ (1).C.roseus was authenticated by the Botanist. Fresh flowers of C.roseus were given orally at the dose of $125 \mathrm{mg} / \mathrm{kg}^{15}$ and N.sativa at dose of $50 \mathrm{~g} / \mathrm{kg} .{ }^{16}$ Data was analyzed on SPSS version 21.0. (IBM, incorporation, USA) Normality of data was checked by Shapiro Wilks test. The continuous variables were analyzed using ANOVA and post Hoc Tukey-Cramer tests. The significant $\mathrm{p}$-value was taken at $\leq 0.05$.

\section{RESULTS}

The results of body weight and blood glucose levels on Days 0, 7 and 14 are shown in tables I and II. Body weight showed significant difference on day 14th $(P=0.001)$ on day 14 th, but not on Days 0 and 7 as shown in table-I $(P>0.06$ and $>0.07$ respectively). Significant differences for blood glucose were observed among groups on different days $(P=0.001)$ as indicated by $F$ - ratio and $p$ - value of analaysis of variance. Blood glucose as high as $\geq 350 \mathrm{mg} / \mathrm{dl}$ was noted in the alloxan treated rats on days 7 and 14 with significant $P$ - value $(P=0.0001)$. Both C.roseus ad N.sativa showed blood glucose lowering potential but this effect was less when compared to glimepiride $(P=0.001)$. However, $C$. roseus was more effective compared to N.sativa 
$(P=0.001)$ in reducing blood glucose. Findings suggest that $\mathrm{C}$. roseus and $\mathrm{N}$. sativa possess glucose regulating potential.

In summary, the glimepiride was most effective in lowering blood glucose levels compared to $\mathrm{C}$. roseus and N.sativa, but later also showed blood glucose lowering effects.

\begin{tabular}{|c|c|c|c|}
\hline & \multicolumn{3}{|c|}{ Mean $\pm S . D$ (grams) } \\
\hline & Day 0 & Day 7 & Day 14 \\
\hline Control & $235.0 \pm 8.4$ & $228.0 \pm 23$ & $228.0 \pm 23$ \\
\hline $\begin{array}{l}\text { Alloxan treated } \\
\text { control }\end{array}$ & $\begin{array}{c}225.4 \pm \\
10.8\end{array}$ & $225.8 \pm 42$ & $172.2 \pm 17$ \\
\hline $\begin{array}{l}\text { Catharanthus } \\
\text { roseus }\end{array}$ & $\begin{array}{c}241.1 \pm \\
16.5\end{array}$ & $239.7 \pm 19$ & $211.0 \pm 40$ \\
\hline Nigella Sativa & $\begin{array}{c}241.1 \pm \\
16.5\end{array}$ & $\begin{array}{c}230.0 \pm \\
10.5\end{array}$ & $\begin{array}{c}192.8 \pm \\
21.7\end{array}$ \\
\hline Glimepiride & $\begin{array}{c}241.1 \pm \\
16.5\end{array}$ & $239.9 \pm 24$ & $223.5 \pm 30$ \\
\hline$p$-value & $P \geq 0.06$ & $P \geq 0.07$ & $P=0.001$ \\
\hline
\end{tabular}

Table-l. Body weight in experimental animals $(n=40)$

\begin{tabular}{|l|c|c|c|}
\hline \multirow{2}{*}{} & \multicolumn{3}{|c|}{ Mean \pm S.D (mg/dl) } \\
\hline Control & Day 0 & Day 7 & Day 14 \\
\hline Alloxan treated & $88.7 \pm 12.8$ & $88.7 \pm 12.8$ & $82.4 \pm 14.5$ \\
\hline control & $233.9 \pm$ & $248.1 \pm$ & $340.0 \pm$ \\
\hline Catharanthus & 27.9 & 53.8 & 38.5 \\
\hline roseus & $404.5 \pm$ & $192.6 \pm$ & $191.2 \pm$ \\
\hline Nigella Sativa & $211.3 \pm$ & $224.3 \pm$ & $231.2 \pm$ \\
\hline Glimepiride & 49.9 & 58.5 & 59.4 \\
\hline p-value & $209.2 \pm$ & $182.8 \pm$ & $167.0 \pm$ \\
\hline
\end{tabular}

Table-II. Blood glucose level in experimental animals $(n=40)$

\section{DISCUSSIONS}

The present study is an original research work conducted at the animal house of Isra University. Currently, obesity is projecting as multiplying concern of ubran population. Obesity is one of the risk factors for $\mathrm{DM}$, and is a metabloic disorder primarily of glucose metabolism. There is an urgent need to search into alternative molecules of herbal origin which may prove helpful in controlling obesity and diabetes mellitus both.

The oral antidiabetic drugs provide good glycemic control along with beneficial effects on dyslipidemia, ${ }^{17}$ however, few studies indicated that these drugs are associated with risk of ischemic heart disease ${ }^{18}$ and cardiac failure..$^{19}$ Thus, achievement of better glycemic control with minimal side effects is still a challenge of modern therapeutics. ${ }^{20}$ The present study provides an insight into new herbal remedy for controlling hyperglycemia. Present study compared the blood glucose lowering effects of $\mathrm{C}$. roseus and N.sativa compared with glimepiride.

A previous study of Kaleem, et al ${ }^{21}$ reported the effects of N.sativa to protamine zinc insulin for blood glucose lowering and lipid peroxidation in streptozocin induced diaebtic rats. It was reported $^{21}$ that the N.sativa reduced blood glucose and exerted antioxidant effect in animal model.

The Natarajan, et al ${ }^{22}$ studied effect of C. roseus in alloxan induced diaebtic rats. The study reported positive effects on blood glucose and lipid levels. The findings of previous studies are comparable to present study.

The study of Ibrahim, M. et al ${ }^{23}$ aimed to evaluate antidiabetic and antibacterial effects of whole plant extract of $\mathrm{C}$. roseus in adult female Wistar albino rats, and reported that the blood glucose was reduced with a concomitant increase in body weight in rats. The findings are in agreement with present study.

The Jayanthi, et $\mathrm{al}^{24}$ studied blood glucose lowering effects of $\mathrm{C}$. roseus in alloxan induced diabetic rats. The body weight was increased and blood glucose reduced to normal. The findings of present study also parallel to above mentioned report.

The Rajashree, et $\mathrm{a}^{25}$ reported that the blood glucose lowering effect of $\mathrm{C}$. roseus results through an increase in glucose utilization by peripheral tissues or by enhanced secretion of insulin from the $\beta$-cells. The findings are also comparable to present study. 
Another study by Mostafa, et $\mathrm{al}^{26}$ compared the blood glucose lowering effect of glimepiride with C. roseus, azadirachta indica, and allium sativum. Among herbs, the most potent glucose lowering agent was the azadirachta indica which was as better as glimepiride followed by $\mathrm{C}$. roseus.

On the basis of witnessed observations of present study, it is reported that the $\mathrm{C}$. roseus and N.sativa regulate and reduce blood glucose in alloxan induced diabetic rats. Further studies are recommended to be conducted in the future.

\section{CONCLUSIONS}

The present study concludes that the Catharanthus roseus and Nigella sativa regulate blood glucose in alloxan induced diabetic rat. Further studies are recommended to confirm the finidngs of present study.

Copyright@ 07 May, 2015.

\section{REFERENCES}

1. Shukla N, Joshi A, Dubey BK. Antidiabetic Activity of Ethenolic Extract of Albizzia Leebeck In AlloxanInduced Diabetic Rats. World J Pharmaceutical Res $2012 ; 1$ :1350-60.

2. Rchid $H$, Chevassus $H$, Nmila R, Guiral C, Petit P, Chokairi $M$, et al. Nigella sativa seed extracts enhance glucose-induced insulin release from rat-isolated Langerhans islets. Fundamental Clin Pharmacol $2004 ; 18: 525-9$.

3. Bnouham M, Ziyyat A, Mekhfi H, Tahri A, Khaleq A. Medicinal plants with potential antidiabetic activity. Diabet Metabol $2006 ; 14: 1-25$.

4. Ibrahim M, Sughra MS, Lakshmi MN. Pharmacological evaluation of Cathranthus roseus. Int 'I J Pharmaceut Applic $2011 ; 2: 165-73$.

5. Singh S, Vats N, Suri P, Shyam SR, Kumria MML, Rangnathan S, Sridhran K. Effect of an antidiabetic extract of Catharanthus roseus on enzymic activities in streptozotocin induced diabetic rats. J Ethnopharmacol $2001 ; 76: 269-77$.

6. Nammi S, Boini MH, Lodagala SD, Behara RBS. The juice of fresh leaves of Catharanthus roseus Linn. reduces blood glucose in normal and alloxan diabetic rabbits. BMC Compl Alter Med 2003 ; 3 :4-8.

7. Arayne MS, Sultana N, Mirza AZ, Zuberi MH, Siddiqui FA. In-vitro hypoglycemic activity of methanolic extract of some indigenous plants. Pak J Pharmaceut Sci 2004 ; 20 :268-73.

8. Zaoui A, Cherrah Y, Alaoui K, Mahassine N, Amarouch $\mathrm{H}$, Hassar M. Effects of Nigella sativa fixed oil on blood homeostasis in rat. J Ethnopharmacol 2002 ; 79 :23-6

9. Kanter M. Effects of Nigella sativa and its Major Constituent, Thymoquinone on Sciatic Nerves in Experimental Diabetic Neuropathy. Neuroche Res 2007 ; 23 :87-96.

10. Paarakh PM. Nigella sativa Linn- A comprehensive review. Indian J Prod Resour 2010 ; 1 :409-29.

11. Farah KM, Atoji Y, Shimizu Y, Takewaki T. Isulinotropic properties of Nigella sativa oil in Streptozotocin plus Nicotinamide diabetic hamster. Rec Veter Science 2002 ; 73 :279-82.

12. Rchid H, Chevassus H, Nmila R, Guiral C, Petit P, Chokairi $M$, et al. Nigella sativa seed extracts enhance glucose-induced insulin release from rat-isolated Langerhans islets. Fundamental Clin Pharmacol 2004 ; $18: 525-9$.

13. Farah KM, Atoji $Y$, Shimizu Y,Shiina T, Nikami $H$, Takewaki T. Mechanisms of the hypoglycaemic and immunopotentiating effects of Nigella sativa L. oil in streptozotocin-induced diabetic hamsters. Res Veter Sci 2004 ;77: 23-9.

14. Ilaiyaraja $N$, Khanum F. Nigella sativa L- A review of therapeutic applications. J Herb Med Toxicol 2010 ; 4:1-8.

15. Karuna R, Ramesh B, Singareddy R, Sreenivasa RY, Saralakumari D. Antihyperglycemic activity of Catharanthus roseus leaf powder in streptozotocininduced diabetic rats, J Pharmacognosy 2010 ; 2 :1958.

16. Mansi KMS. Effects of Oral administration of water extract of Nigella sativa on the Hypothalamus pituitary adrenal Axis in Experimental Diabetes. Int` J Pharmacol 2006 ; 2 :104-9.

17. Haberbosch W. Effects of thiazolidinediones on dyslipidemia in patients with type 2 diabetes. Are all equally vasoprotective. Herz 2007 ; 32 : 51-7.

18. Nissen SE, Wolski K. Effect of rosiglitazone on the risk of myocardial infarction and death from cardiovascular causes. NEJM 2007 ; 356 : 2457-71.

19. Granberry MC, Hawkins JB, Franks AM. Thiazolidinediones in patients with type 2 diabetes mellitus and heart failure. Am J Health Syst Pharmacy 
2007; 64: 931-6.

20. Eric B. Attitudes towards holistic complementary and alternative medicine: a sample of healthy people in Turkey. J Clin Nurs 2007;16:761-8.

21. Kaleem M, Kirimani D, Asif M, Ahmed Q, Bilqees B. Biochemical effect of Nigella sativa $L$ seed in diabetic Rats. Turk J Biol 2007 ; 3 : 95-102.

22. Natarjan AK, Ahmed ZS, Sundaresan SA, Sivaraj K, Devi B, Kumar S. Effect of Aqueous Flower Extract of Catharanthus roseus on Alloxan Induced Diabetes in Male Albino Rats. Int' I J Pharmaceut Sci Drug Res $2012 ; 4$ : 150-3.

23. Ibrahim M, Sughra MS, Lakshmi MN. Pharmacological evaluation of Cathranthus roseus. Int'I J Pharmaceut
Applic $2011 ; 2: 165-73$.

24. Jayanthi M, Sowbala N, Rajalakshmi G, Kanagavalli $\mathrm{U}$, Sivakumar V. Study of anti-hyperglycemic effect of catharanthus roseus in alloxan induced diabetic rats. Int`I J Pharmacy Pharmaceut Sci 2010;2 :114-6.

25. Rajashree R, Bhat P, Parineetha, Ravishankar MV. Effects of a Mixture of Salacia reticulata $W$. and Catharanthus roseus L. Extracts in StreptozotocinInduced Juvenile Diabetic Rats. J Physiol Biomed Sci $2011 ; 24: 5-8$.

26. Mostafa M, Choudhury ME, Hossain MA, Islam MZ, Islam MS, Sumon-Bangal MH. Antidiabetic Effects Of Catharanthus Roseus, Azadirachta Indica, Allium Sativum And Glimepride In Experimentally Diabetic Induced Rat. Veter Med 2007 ; 5 :99-102.

\section{AUTHORSHIP AND CONTRIBUTION DECLARATION}

\begin{tabular}{|c|c|c|c|}
\hline Sr. \# & Author-s Full Name & Contribution to the paper & Author $=\mathbf{s}$ Signature \\
\hline 1 & Dr. Palwasha Abbasi & $\begin{array}{l}\text { Concept of study, data } \\
\text { collection, data analysis } \\
\text { and manuscript writing and } \\
\text { checking }\end{array}$ & \\
\hline 2 & Dr. Abdul Rahim Memon & $\begin{array}{l}\text { Concept of study, data } \\
\text { collection, data analysis } \\
\text { and manuscript writing and } \\
\text { checking }\end{array}$ & \\
\hline 3 & Dr. Sadia Tabassum Abbasi & $\begin{array}{l}\text { Concept of study, data } \\
\text { collection, data analysis } \\
\text { and manuscript writing and } \\
\text { checking }\end{array}$ & \\
\hline 4 & Dr. Sadia Kazi & $\begin{array}{l}\text { Concept of study, data } \\
\text { collection, data analysis } \\
\text { and manuscript writing and } \\
\text { checking }\end{array}$ & \\
\hline 5 & Dr. Shomail Siddiqui & $\begin{array}{l}\text { Concept of study, data } \\
\text { collection, data analysis } \\
\text { and manuscript writing and } \\
\text { checking }\end{array}$ & \\
\hline
\end{tabular}

